\title{
The Art of Manipulating Nutrient Bioprocessing In Ruminants: Behind the Rumen Wheel
}

\begin{abstract}
Akbar Nikkhah ${ }^{*}$
Chief Highly Distinguished Professor, Department of Animal Sciences, University of Zanjan, Iran

Received date: June 25, 2015, Accepted date: June 26, 2015, Published date: June 30, 2015 distribution, and reproduction in any medium, provided the original author and source are credited.

\section{Editorial}

This article emphasizes the art of managing rumen fermentation in securing efficient nutrient bioprocessing and economy-boosting production in modern dairy and beef ruminant production. A special focus is made to not overestimate post-rumen nutrient assimilation capacity. Rumen is where any modern ruminant enterprise must concentrate on towards improved food safety and security.
\end{abstract}

*Corresponding author: Akbar Nikkhah, Chief Highly Distinguished Professor, Department of Animal Sciences, Faculty of Agricultural Sciences, University of Zanjan, Zanjan, Iran, National Elite Foundation, Tehran, Iran, Tel: +98-24-350-328-01; Fax: +98-24-350-332-02; E-mail: nikkhah@znu.ac.ir

Copyright: ( 2015 Nikkhah A. This is an open-access article distributed under the terms of the Creative Commons Attribution License, which permits unrestricted use,

\section{Philosophy and Discussion}

Nutrient bioprocessing efficiency in modern ruminant production depends increasingly on maintaining healthy and metabolically stable rumen environment [1-3]. Controversies have existed on the relative ultimate importance of rumen versus post-rumen gut in improving dairy and beef production without compromising or even jeopardizing ruminant health and longevity [4-8]. For instance, maximizing starch bioprocessing efficiency in high-merit ruminants is of utmost significance to maintaining economical levels of milk and beef production. However, increased production must not be targeted through unwarranted increases in rumen fermentation that would adversely affect rumen and ruminant health and economy [9-11].

Neither recklessly raising extent and rate of rumen starch fermentation nor fearfully limiting rumen starch availability and overfocusing on post-rumen starch bioprocessing will yield real success. The art of nutrient bioprocessing in modern ruminants in embedded in capacious management of rumen fermentation and leading the post-rumen gut to just complement the bioprocess towards improved efficiency. Quantitatively, assimilation and bioprocessing of no less than $70-80 \%$ of dietary starch and neutral detergent fibre must be accomplished in rumen. This is because the small intestine possesses limited capacities to effectively assimilate starch. In addition, any increased fermentation of undigested or partially digested nutrients in the large intestine elevates waste and reduced efficiency $[12,13]$.

Ruminant management must be led in ways that ensure no overlimit nutrient is by-passed the rumen either in undigested or insufficiently-digested forms, blindly hoping to be effectively assimilated in the post-rumen [14]. Rumen serves as an engine for the ruminant machine to work efficiently and sustainably [15]. To drive the ruminant productively and healthfully, the wheel to be seated behind is certainly the rumen ecology management. No overfocuses on post-rumen sections must be made, as they are to merely complement the rumen achievements and not more.

Creating and securing a global art of effective rumen fermentation depends highly on optimized forage nutrition, grain processing and management, grain feeding strategies, ration preparation and presentation systems, feeding frequency and sequence, and suitably adopted dairy and beef production strategies [10-12]. The latter includes lactation cycles properties, growing and fattening duration, dietary adaptation techniques, dry period modifications, reproduction management and supplement nutrition. These players must be managed and set to maximise nutrient efficiency through a global leadership of rumen nutrient bioprocessing in modern ruminant production.

\section{Conclusion}

Rumen must become the gold-goal of any modern ruminant production in managing nutrient bioprocessing for maximal efficiency and economics. Overattention to the post-rumen gut would be a first and foremost step towards catastrophic situations in animal health and food safety and security in the new times.

\section{Acknowledgment}

Thanks to Iran's Ministry of Science Research and Technology, National Elite Foundation, and University of Zanjan for supporting the author's global programs of optimizing science edification in the new millennium.

\section{References:}

1. Nikkhah A (2012) Time of Feeding an Evolutionary Science. Lap Lambert Publishing, GmbH \& Co. KG, Germany.

2. Nikkhah A (2015) Optimizing Dairy Herd Starch Efficiency via Strategic Heifer Management. Int J Dairy Sci Process 2: 1-2.

3. Nikkhah A (2015) Grain Serving of Postmodern Dairy Cattle: Benefits of Processing Overestimated. Int J Dairy Sci Process 2: 14-15.

4. Nikkhah A (2015) Dry or Steam Rolling of Soft Grains: Dairy and Beef Bioprocessing Perspectives. J Bioprocess Biotech 5: e124.

5. Orskov ER (1986) Starch digestion and utilization in ruminants. J Anim Sci 63: 1624-1633.

6. Huntington GB (1997) Starch utilization by ruminants: from basics to the bunk. J Anim Sci 75: 852-867.

7. Huntington GB, Harmon DL, Richards CJ (2006) Sites, rates, and limits of starch digestion and glucose metabolism in growing cattle. J Anim Sci 84: E14-E24.

8. Theurer CB, Huber JT, Delgado-Elorduy A, Wanderley R (1999) Invited review: summary of steam-flaking corn or sorghum grain for lactating dairy cows. J Dairy Sci 82: 1950-1959.

9. Nikkhah A (2015) On Rumen Microbial Evolution: Food Security Prospects. J Food Nutri 2: 011.

10. Nikkhah A (2015) Gut Adaptation to Healthy Starch Assimilation in Dairy Ruminants: A Lifetime Development. Adv Dairy Res 3: e117.

11. Nikkhah A (2015) Production Curve Management of Starch Nutrition in Ruminants: A Global Biotechnique. J Bioprocess Biotech 5: e123. 
Citation: Nikkhah A (2015) The Art of Manipulating Nutrient Bioprocessing In Ruminants: Behind the Rumen Wheel. J Bioprocess Biotech 5: e134. doi:10.4172/2155-9821.1000e134

Page 2 of 2

12. Nikkhah A (2015) The Forage Art in Managing Component Feeding: A Persistent On-Farm Success. EC Agriculture 1: 98-99.

13. Nikkhah A (2015) Cereals Bond Trounces Subacute Rumen Acidosis. Int J Vet Health Sci Res 3: 1-2.
14. Nikkhah A (2014) Grinding as a Most Economical Healthy Bioprocessing Biotechnique of Cereals for Postmodern Ruminants. J Bioprocess Biotech 5: e119.

15. Nikkhah A (2012) Barley grain for ruminants: A global treasure or tragedy. J Anim Sci Biotechnol 3: 22-29. 